\title{
Assessing the impact of cigarette package health warning labels: a cross-country comparison in Brazil, Uruguay and Mexico
}

\author{
James F Thrasher, PhD, MA, MS, (1,2) Victor Villalobos, MS, (I) André Szklo, PhD, ${ }^{(3)}$ Geoffrey T Fong, PhD, ${ }^{(4,5)}$ \\ Cristina Pérez, BA, ${ }^{(3)}$ Ernesto Sebrié, MD, MPH, ${ }^{(6)}$ Natalie Sansone, BA, ${ }^{(4)}$ Valeska Figueiredo, $\mathrm{PhD},{ }^{(3)}$ \\ Marcelo Boado, PhD, ${ }^{(7,8)}$ Edna Arillo-Santillán, MPH, ${ }^{(1)}$ Eduardo Bianco, MD. ${ }^{(8)}$
}

\begin{abstract}
Thrasher JF, Villalobos V, Szklo A, Fong GT, Pérez C, Sebrié E, Sansone N, Figueiredo V, Boado M,Arillo-Santillán E, Bianco E. Assessing the impact of cigarette package health warning labels: a cross-country comparison in Brazil, Uruguay and Mexico. Salud Publica Mex 2010;52 suppI 2:S206-S2I5.
\end{abstract}

\begin{abstract}
Objective. To assess the impact of different health warning labels (HWL). Material and Methods. Data from the International Tobacco Control Survey (ITC Survey) were analyzed from adult smokers in Brazil, Uruguay and Mexico, each of which used a different HWL strategy (pictures of human suffering and diseased organs; abstract pictorial representations of risk; and text-only messages, respectively). Main outcomes were HWL salience and cognitive impact. Results. HWLs in Uruguay (which was the only country with a HWL on the front of the package) had higher salience than either Brazilian or Mexican packs. People at higher levels of educational attainment in Mexico were more likely to read the text-only HWLs whereas education was unassociated with salience in Brazil or Uruguay. Brazilian HWLs had greater cognitive impacts than HWLs in either Uruguay or Mexico. HWLs in Uruguay generated lower cognitive impacts than the text-only HWLs in Mexico. In Brazil, cognitive impacts were strongest among smokers with low educational attainment. Conclusions. This study suggests that HWLs have the most impact when they are prominent (i.e., front and back of the package) and include emotionally engaging imagery that illustrates negative bodily impacts or human suffering due to smoking.
\end{abstract}

Keywords: tobacco; health policy; product labeling; warning; mass media
Thrasher JF, Villalobos V, Szklo A, Fong GT, Pérez C, Sebrié E, Sansone N, Figueiredo V, Boado M,Arillo-Santillán E, Bianco E. Impacto de advertencias sanitarias del empaquetado de cigarros: un análisis comparativo en Brasil, Uruguay y México. Salud Publica Mex 2010;52 supl 2:S206-S2I5.

\section{Resumen}

Objetivo. Evaluar el impacto de diferentes advertencias sanitarias (AS). Material y métodos. Se analizaron datos de la Encuesta Internacional para el Control del Tabaco (ITC Survey), un estudio de fumadores adultos en Brasil, Uruguay y México, tres países con distintas AS (con imágenes de sufrimiento humano y órganos enfermos; con imágenes abstractas del riesgo; mensajes de solo texto, respectivamente). Se analizó prominencia e impacto cognitivo de las AS. Resultados. Las AS de Uruguay (que era el único país con AS en la parte frontal del paquete) tuvieron una mayor prominencia que en Brasil o México. En México, la gente que tenía un nivel de educación mayor eran mas propensos a leer mensajes de advertencia, mientras que educación no se asoció con prominencia en Brasil o Uruguay. Las AS de Brasil tuvieron un mayor impacto cognitivo y conductual que las AS de Uruguay - México. Las AS de Uruguay generaron un menor impacto cognitivo y conductual que las AS de sólo texto en México. En Brasil, los impactos cognitivos fueron los más fuertes entre fumadores con un bajo nivel educacional. Conclusiones. Este estudio sugiere que las AS tienen el mayor impacto cuando son prominentes (por ej. en el frente y la parte trasera del paquete) e incluyen imágenes emocionalmente llamativas que muestran impactos negativos en el cuerpo o sufrimiento humano debido al fumar.

Palabras clave: tabaco; política de salud; etiquetado de productos; aviso; medios de comunicación

(I) Instituto Nacional de Salud Pública. Cuernavaca, Morelos, México.

(2) Arnold School of Public Health, University of South Carolina, South Carolina, USA.

(3) Instituto Nacional de Cancer. Rio de Janeiro, Brasil.

(4) Department of Psychology, University of Waterloo. Waterloo, Ontario, Canada.

(5) Ontario Institute for Cancer Research. Toronto, Ontario, Canada.

(6) Department of Health Behavior, Roswell Park Cancer Institute. Buffalo, New York, USA

(7) Departamento de Sociología, Universidad de la República. Montevideo, Uruguay.

(8) Centro de Investigación para la Epidemia de Tabaquismo. Montevideo, Uruguay.

Received on: February 5,2010 - Accepted on: June 2, 2010

Address reprint requests to: James F.Thrasher, PhD. Department of Health Promotion, Education, and Behavior. Arnold School of Public Health, University of South Carolina. 800 Sumter Street, Room 215, Columbia, SC 29208, USA. E-mail: thrasher@mailbox.sc.edu 
The World Health Organization's Framework Convention on Tobacco Control (WHO-FCTC) promotes the use of strong, effective health warning labels (HWLs) on tobacco product packaging in order to inform smokers and potential smokers of the health risks of smoking. ${ }^{1}$ In particular, the WHO-FCTC stipulates that HWLs on cigarette packaging "should be $50 \%$ or more of the principal display areas but shall be no less than 30\%" and "may be in the form of or use pictures or pictograms." 2 Recent research supports these standards, with consistent evidence that warning labels that combine pictures and text are more effective than text-only messages in engaging smokers, increasing their knowledge about risks, promoting quitting, and decreasing demand for cigarettes. ${ }^{3-11}$ However, further research is needed to assess which pictorial HWL formats and content work best, as well as to assess the potential modification of these effects by subgroup characteristics that contribute to tobacco-related health disparities.
Little is known about whether some types of pictorial images on cigarette packs are more likely than other types to influence smokers' knowledge, attitudes, and behaviors. However, focus groups in Canada, ${ }^{12}$ as well as experimental research in the US, ${ }^{13}$ Mexico $^{14}$ and Brazil ${ }^{15,16}$ suggest that gruesome imagery has greater impact than abstract imagery. This finding is supported by surveys of adult smokers in Uruguay, Thailand, and Australia, which suggest that after each country instituted pictorial HWLs for the first time, the warnings had a lower impact in Uruguay than in the other countries. ${ }^{*}$ This difference can be attributed to the relatively abstract imagery of HWLs in Uruguay (Figure 1), which contrasts with the more gruesome illustrations of smoking consequences in the other countries.

* Thrasher JF, Villalobos V, Cummings KM, Borland R, Yong H-H. Smokers' reactions to health warnings labels with pictorial imagery in Uruguay, Thailand and Australia: Does fear arousing content matter? Under review.

Figure I

Cigarette package health warning label (HWL) characteristics in Brazil, Uruguay \& Mexico, 2008-2009

$$
\text { Brazil (2009) Uruguay (2008) México (2008) }
$$

\begin{tabular}{|c|c|c|c|c|c|}
\hline \multirow{5}{*}{$\begin{array}{l}\mathrm{HWL} \\
\text { format }\end{array}$} & \multirow{2}{*}{$\begin{array}{l}\text { HWL size as } \\
\% \text { of principal } \\
\text { display areas }\end{array}$} & Front & None & $50 \%$ & None \\
\hline & & Back & $100 \%$ & $50 \%$ & $50 \%$ \\
\hline & \multicolumn{2}{|l|}{ Pictures } & Yes & Yes & No \\
\hline & \multicolumn{2}{|c|}{$\begin{array}{l}\text { Years of exposure to } \\
\text { format at data collection }\end{array}$} & 7 (2002-2009) & $2(2006-2008)$ & $4(2004-2008)$ \\
\hline & \multicolumn{2}{|c|}{$\begin{array}{l}\text { Pictorial image type } \\
\text { (number of message } \\
\text { variants) }\end{array}$} & $\begin{array}{l}\text { Diseased organs (4) \& human suffe- } \\
\text { ring imagery (4), abstract imagery ( } 2 \text {, } \\
\text { each with different text }\end{array}$ & $\begin{array}{l}\text { Abstract imagery (4), each with } \\
\text { different text }\end{array}$ & Text only (3) \\
\hline
\end{tabular}




Research has generally not examined whether HWLs formats have different effects across sociodemographic groups within different countries. As tobacco policies and programs have been implemented in highincome countries, smoking has become concentrated within socially disadvantaged groups. ${ }^{17}$ This disparate concentration may also occur in low- and middleincome countries unless policies and programs have even impacts or help offset disparities that arise from certain interventions, including communication interventions to which low SES populations have lower levels of exposure or are less responsive. Warning labels potentially communicate health risks to smokers across all SES groups, and picture warning labels may reach an even greater audience as they overcome issues with literacy. ${ }^{8,18}$ As such, health warning labels could help prevent and/or remediate smoking-related tobacco disparities. In this regard, studies of the differential impact of mass media campaigns are suggestive. Some mass media campaigns impact high- but not low-SES groups ${ }_{r}^{19}$ however, other research has found that emotionally evocative ads and testimonials appear to work better among lower than higher SES groups. ${ }^{20} \mathrm{~A}$ key research question for the future development of HWL messaging policies is whether pictorial HWLs are better than text-only HWLs in influencing low SES groups, and whether testimonial and emotionally evocative pictorial HWLs may do this more effectively than other types of pictorials. We address this question in this article by analyzing data from International Tobacco Control Policy Evaluation Project (ITC Project) surveys in three Latin American countries with HWLs that likely vary in emotional intensity that they provoke.

\section{Health warning labels and the tobacco control context in Brazil, Uruguay and Mexico}

At the time of ITC survey data collection in 20082009, the health warning labels in Brazil, Uruguay and Mexico were quite different (Figure 1). In Brazil, HWLs covered $100 \%$ of the back of each cigarette pack, whereas they covered 50\% of the back in Uruguay and Mexico. Unlike Brazil and Mexico, Uruguay's HWL also covers the front of the pack. Brazil has had pictorial warning labels since 2002, ${ }^{21}$ which were revised in 2004 and again in 2009, ${ }^{16}$ after the current study data were collected. ${ }^{16}$ The 2004 HWLs included four images of human suffering, four images of gruesome diseased organs and death, and two abstract representations of poison (dead rat) and impotence (limp cigarette). Uruguay implemented its first round of eight pictorial HWLs in 2006, with a second round in 2008, and sub- sequent rounds after data were collected. The first two rounds of pictorial HWLs consisted of abstract representations of smoking-related consequences, which in the second round took the form of a vial with skull and crossbones, dynamite, and a tombstone. The text-only HWLs in Mexico have been in existence since 2004, and include three messages (Smoking causes cancer and emphysema; Quitting smoking reduces important health risks; Smoking during pregnancy increases risk of premature birth and low birthweight babies).

This paper uses cross-sectional data from these three countries with distinct HWL policies in order to explore the following hypotheses: 1) In Mexico, which has text-only HWLs, greater HWL salience and cognitive impact will be associated with higher educational attainment, whereas these associations will be negative in Brazil and Uruguay, which have pictorial HWLs; 2) In Uruguay, which is the only country with a HWL on the front of the package, HWL salience will be greater than in other countries; In Brazil HWLs will be more salient than in Mexico, due to having more space dedicated to the HWL; 3) The cognitive and behavioral impact of HWLs will be greater in Brazil than in Uruguay, which will be greater than in Mexico.

\section{Material and Methods}

Study sample: As part of the International Tobacco Control Policy Evaluation Project (ITC-Project), data were collected from adult smokers in Brazil (Wave 1, April to June 2009), Uruguay (Wave 2, September to December 2008), and Mexico (Wave 3, November to December 2008). At the time of analysis, there was only one survey wave for Brazil, which occurred when its HWLs had included pictorials for seven years; hence, we selected the most recent ITC survey administrations in Uruguay and Mexico, so that the length of time that participants would have been exposed to the HWLs was as comparable as possible (since 2006 and 2004, respectively). In Brazil, telephone-administered surveys were conducted with adult smokers using an area stratified random sampling strategy, yielding a representative sample of 1215 smokers who lived in three of the four largest cities in Brazil (Rio de Janeiro, Porto Alegre, and Sao Paulo). For Brazil, the household telephone contact rate was $31.7 \%$ and the cooperation rate among smokers identified as eligible was $85.2 \%$. Eligible smokers were those who smoked at least monthly and at least 100 lifetime cigarettes. The Uruguayan and Mexican administrations of the ITC surveys were conducted using a similar stratified, multi-stage sampling strategy that involved face-toface interviews with randomly selected adult smokers, defined as those who had smoked at least once during 
the previous week and at least 100 lifetime cigarettes (for details, see Thrasher et al., 2009). The wave 1 Uruguayan sample consisted of households in the capital city of Montevideo, where $40 \%$ of the countries 3.5 million people live. In Montevideo, 95\% of households selected were contacted and $76 \%$ of selected smokers agreed to participate. At wave $2(\mathrm{n}=1378)$, which comprises the analytic sample for the present study, $66 \%$ (585/885) of participants were successfully re-interviewed, with replenishment of smokers in Montevideo $(\mathrm{n}=391)$ and new samples $(n=402)$ selected using the same procedures in four additional smaller cities (Salto, Maldonado, Durazno, and Rivera), whose population ranged from 30000 to 100000 . The household enumeration and participation rates in these new cities were $88 \%$ and $78 \%$, respectively. People who no longer smoked $(n=85)$ were excluded from the analytic sample. In Mexico, the wave 1 (2006) sampling frame consisted of households within each of four of the six largest cities in Mexico (Mexico City, Guadalajara, Tijuana, and Ciudad Juárez), but which was expanded at wave 3 (2008) to include three additional cities that are amongst the twelve most populous in Mexico (Monterrey, Puebla, and Mérida). The household enumeration rate at wave 1 was $64 \%$ and the cooperation rate among selected participants was $89 \%$. At wave 2 in 2007, $70 \%$ (756/1079) were successfully followed up, with replenishment of this sample with 289 randomly selected smokers who lived within the same census tracts where the loss to follow up occurred. The wave 3 sample $(n=2010)$, which comprises the analytic sample for the present study, includes $73 \%$ (762/1045) of those followed from wave 2, a replenishment sample of 300 smokers randomly selected from the same census tracts, as well as new samples in three cities $(\mathrm{n}=813)$ and in Mexico City $(\mathrm{n}=135)$. Household contact and cooperation rates for this new sample were $79 \%$ and $70 \%$, respectively. People who were no longer smokers $(n=149)$ were excluded from the analytic sample. For each country, sampling weights were developed to account for the likelihood of participant selection. To produce more efficient estimates of association, ${ }^{22}$ the weights used for model estimation were rescaled to sum to the sample size within each country. Protocols were approved by ethics review boards in each country (INCA, Brazil; Universidad de la República, Uruguay; INSP, México). Before participating, Brazilian smokers provided oral informed consent, while Uruguayan and Mexican smokers provided written informed consent.

\section{Measurement}

Exposure and reactions to health warning labels: Warning label salience was assessed with two questions: how often smokers noticed HWLs; and how often they read or looked closely at them. Responses for each were dichotomized ( $1=$ often or very often vs. $0=$ never or once in a while in Uruguay and Mexico or vs. $0=$ never, rarely or sometimes in Brazil). Cognitive impact was assessed with three questions: how much HWLs made participants think about the health risks of smoking; how much HWLs made participants think about quitting; and how often HWLs made them think about quitting. For simple comparative analises, response options were dichotomized (i.e., $0=$ none vs. $1=a$ little, somewhat, or a lot for the first two questions; $0=$ none or $a$ little vs. $1=a$ lot for the third). These three questions were also rescaled to have the same range of responses and averaged together to create a scale, which had good internal consistency in all three countries (alpha $=0.77,0.78$, and 0.71 in Brazil, Uruguay and Mexico, respectively). Finally, assessment of behavioral impact of HWL involved asking if, in the last month, health warnings had stopped participants from having a cigarette when they were about to smoke one (i.e., $0=$ never, $1=$ at least once).

Smoking-related variables: Smokers were asked if they smoke everyday or less frequently (coded as 1 and 0 , respectively). Participants were also asked how much smoking had harmed their health, as well as how much they worried that smoking would harm them in the future. Response options for each of these two questions (not at all, somewhat, a lot) were dummy coded, with "not at all" as the reference group. Finally, participants were asked if they had heard of or ever used a toll free quit line.

Sociodemographics: Sociodemographic characteristics were assessed with standard questions on sex, age, and educational attainment. Although educational systems vary in each country, a four-level variable was a created that was a meaningful within and across groups. For Brazil, the reported number of years of education were collected and recoded to reflect comparable levels of attainment: primary school or less, $0-4$ years; secondary school, 5-8 years; high school, 9-11 years; and university or higher, 12 or more years. For Uruguay and Mexico, categorical variables were recoded to reflect primary school or less, secondary school, high school or technical school, and university or higher. In pooled analyses, differences between countries were assessed with dummy variables that treated Mexico as the referent group. Interactions were tested by multiplying the country dummy variable with the variable of interest.

\section{Analysis}

All analyses were conducted using STATA, version 9. Sociodemographics and smoking-related character- 
istics were assessed without adjusting for the survey design. T-tests and chi-square tests were used to assess differences in these characteristics across countries, without survey adjustment. All other univariate (i.e., health warning label indicators and quit line variables), bivariate, and multivariate analyses involved adjustment for survey design and sampling weights. In models stratified by country, multivariate logistic models were estimated for dichotomous HWL indicators (i.e., salience variables and behavioral impact), and linear regression models for the continuous, cognitive impact HWL scale. In these models, HWL indicators were regressed on sociodemographics, daily smoking, and risk perceptions. In pooled analyses, the same dependent and independent variables were assessed, while also including dummy variables for country and, where appropriate, a variable to express the interaction between country and the variable of interest. For all analyses, $p$-values $<0.05$ were used to indicate statistical significance.

\section{Results}

Table I shows the characteristics of the analytic samples for this study. The Brazilian sample was slightly older (mean age 44.4) and had higher educational attainment than the Uruguayan and Mexican samples (mean age 40.8 and 40.2, respectively). Participants in Brazil also held stronger beliefs about the harm they had already experienced from tobacco use, with similar levels of perceived harm among Uruguayan and Mexican participants. Brazilian and Mexican participants had comparable expectations about future harms they would experience from smoking, with Uruguayan participants

Table I

Sample characteristics and responses to health Warning labels in Brazil, Uruguay and Mexico

Characteristics

$\begin{array}{ccc}\text { Brazil } & \text { Uruguay } & \text { Mexico } \\ (n=|2| 5) & (n=\mid 294) & (n=\mid 867)\end{array}$

$\operatorname{Age}^{c, f}($ mean)

Male $e^{c, d, l}(\%)$

Education $^{\text {c.f., }}(\%)$

Daily smokerf, $(\%)$

Smoking has harmed healthc,

(\%)

Smoking will harm healthc,i

(\%)

Quit line* (\%)

Responses to health warning labels (HWLs)* (\%)

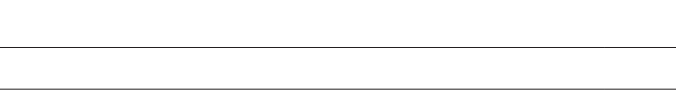

Primary or less 10.2

Secondary 23.2

$\begin{array}{lll}44.4 & 40.8 & 40.2\end{array}$

$\begin{array}{lll}23.2 & 44.4 & 28.7\end{array}$

High or technical school

University or more

Daily

Not at all

Some 40.6

A lot 41.1

Not at all 9.0

Some 33.2

A lot 57.8

\% heard of toll-free quit line ${ }^{\mathrm{c}, \mathrm{fi}}$

$\%$ ever called toll-free quit line ${ }^{c, f}$. 7.1

Noticed HWLs often or very often ${ }^{c, i}$

Read or looked closely at HWLs often or very often ${ }^{c, i}$

HWLs made you think about harms of smoking c,f,i

HWLs made you think about quitting $\mathrm{c,fi}, \quad 72.6$

Thought a lot about quitting because of $\mathrm{HWLs} \mathrm{s}^{\mathrm{c}, \mathrm{fi}}$

\begin{tabular}{lll}
57.3 & 49.1 & 61.4 \\
\hline & 25.0 & 29.3
\end{tabular}

Stopped smoking when about to light a cigarette because of HWLs, c,i,

\begin{tabular}{ll}
\hline Want less $\mathrm{HWL}$ information & 2.7 \\
\hline Want equal HWL information & 40.4 \\
\hline Want more HWL information ${ }^{\text {cf,i }}$ & 56.8
\end{tabular}

\begin{tabular}{ccc}
38.2 & 17.0 & 26.3 \\
\hline 2.7 & 6.8 & 4.3 \\
\hline 40.4 & 61.5 & 48.6 \\
\hline 56.8 & 31.6 & 47.12
\end{tabular}

* Survey-adjusted estimates shown and compared for quitline and HWL-related questions, but not for other questions

a BR vs. UY different at $p<0.0$ I; $\quad{ }^{b} B R$ vs. UY different at $p<0.05 ; \quad$ c BR vs. UY different at $p<0.001$

${ }^{d} B R$ vs. MX different at $p<0.01 ; \quad$ e BR vs. MX different at $p<0.05 ; \quad{ }^{f} B R$ vs. MX different at $p<0.00$ I

g UY vs. MX different at $p<0.0$ I; $\quad$ h UY vs. $M X$ different at $p<0.05 ; \quad$ i $U Y$ vs. $M X$ different at $p<0.00$ I 
indicating lower expectations about future harms. Brazilian participants were much more likely than Uruguayan or Mexican participants to have heard of the quit line (i.e., $93 \%$ vs $39 \%$ and $29 \%$, respectively) and to have called the quit line (7\% vs $1 \%$ and $2 \%$, respectively). When assessing warning label responses, indicators of warning label salience (noticing and reading HWLs often or very often) were significantly higher in Uruguay $(62.3 \%$ and $42.4 \%$, respectively) than in either Brazil (45.5\% and $29.5 \%$, respectively) or Mexico (42.9\% vs. $31.9 \%$, respectively). However, indicators of cognitive processing and behavioral impact of HWLs were all higher in Brazil (38\% to $84 \%$ ) than in either Uruguay (6\% to $63 \%$ ) or Mexico (12\% to $72 \%$ ), with Uruguayans indicating lower levels of cognitive impact than Mexicans. Most Brazilian participants also indicated that they wanted more information on HWLs (57\%), which was higher than their Uruguayan and Mexican counterparts (32\% and $47 \%$, respectively).

\section{Noticing and reading/looking at HWLS}

Logistic regression models were estimated to assess factors associated with the noticing and reading/looking at HWLs within and across countries (Table II). In the case of Mexico, educational attainment had a positive, independent association with salience in both models $(\mathrm{B}=0.14, p<0.05 ; \mathrm{B}=0.18, p<0.01)$, whereas education had no statistically significant association with either outcome in Brazil or Uruguay. In the models stratified by country, other sociodemographic and smoking-related variables generally indicated no statistically significant association with HWL salience indicators, or they were associated with one, but not the other outcome. Data were then pooled across countries to assess countrylevel effects and interactions. In the model estimating predictors of noticing HWLs, higher educational attainment was positively associated $(B=0.08, p<0.05)$, and those who perceived a lot of future harm from smoking

Table II

MULTIVARIATE LOGISTIC MODELS REGRESSING HEALTH WARNING LABEL SALIENCE INDICATORS ON SOCIODEMOGRAPHICS AND SMOKING-RELATED VARIABLES, BY COUNTRY AND POOLED

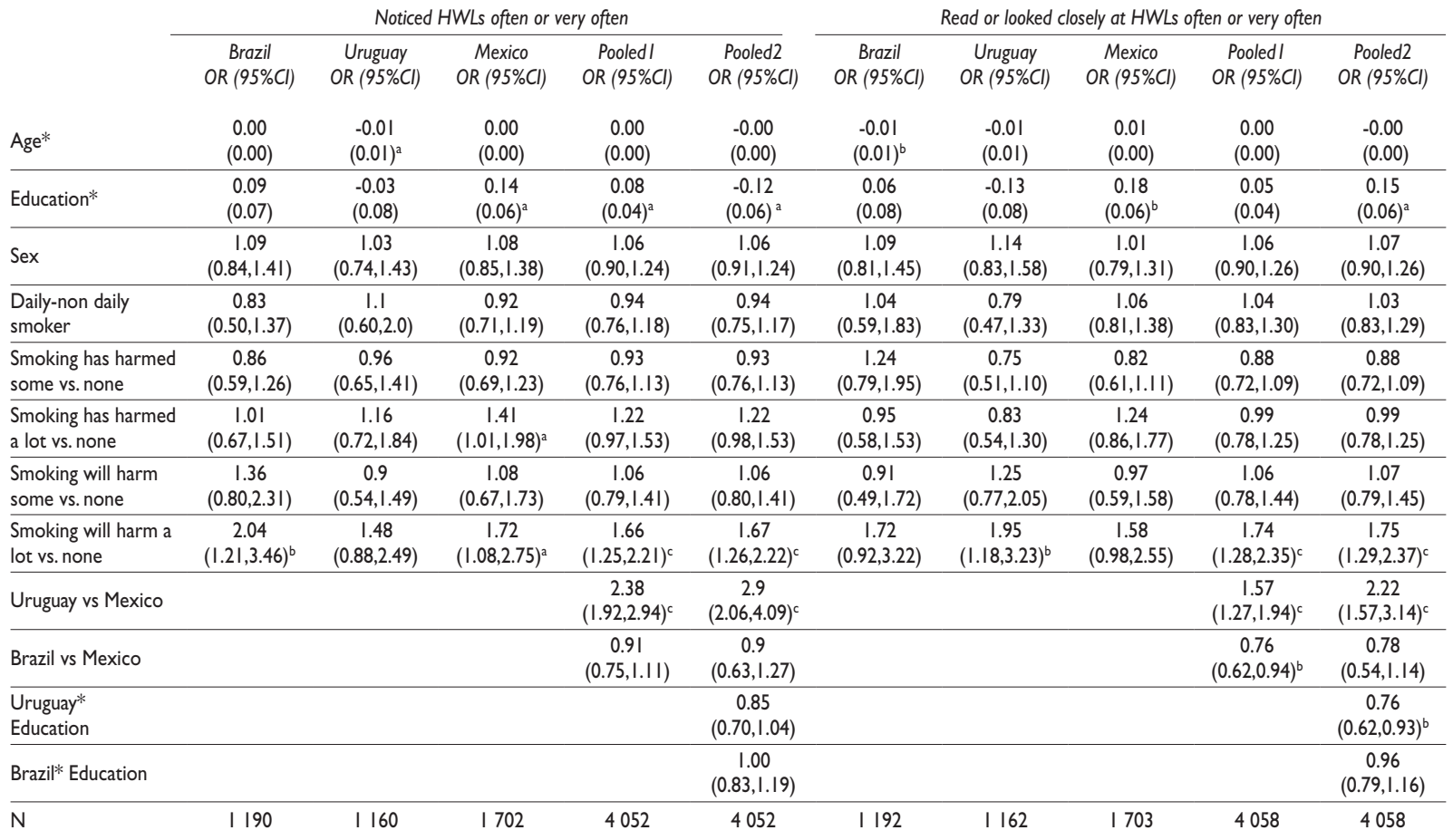

* Estimates shown for age and education are beta coefficients, not odds ratios, and thus, the value of an age or education coefficient under the null hypothesis is 0 , not I

${ }^{\mathrm{a}} p<0.01 ;{ }^{\mathrm{b}} p<0.05 ;{ }^{\mathrm{c}} p<0.001$ 
were more likely to notice HWLs than those who did not perceive these harms (AOR=1.66). Furthermore, Uruguayans were more likely than Mexicans to notice HWLs (AOR=2.38), with no difference between Mexicans and Brazilians. Tests of interaction between education and country were not significant. In the pooled model to assess predictors of reading HWLs, reading was also significantly higher among Uruguayans than among Mexicans, but a statistical interaction was found between Uruguay and education such that the positive association between education and reading HWLs in Mexico was significantly stronger than the lack of association found in Uruguay.

\section{Cognitive impact of HWLS}

Linear regression models were also estimated, regressing the scale of cognitive HWL impact on sociodemographics and smoking-related variables (Table III). In the models stratified by country, education was inversely associated with cognitive impacts in Brazil $(B=-0.20$, $p<0.001)$, but unassociated in Uruguay and Mexico. Non-daily smokers and those with greatest perceived current and future harms due to smoking were also generally more likely to report cognitive impacts due to HWLs. These relationships maintained statistical significance in the pooled, multivariate model, where Uruguayans were significantly less likely than Mexicans to experience cognitive HWL impacts $(B=-0.09, p<0.05)$, whereas Brazilian counterparts were more likely to experience these impacts $(\mathrm{B}=0.80, p<0.001)$. A second pooled model indicated a statistically significant interaction between Brazil and education, such that the inverse association found between education and cognitive impacts from HWLs was significantly stronger than the lack of association found in Mexico.

\section{Behavioral impact of HWLs}

Finally, logistic regression models were estimated to determine the factors associated with reporting that in the last month, HWLs stopped a participant from

Table III

MULTIVARIATE REGRESSION MODELS OF COGNITIVE AND BEHAVIORAL IMPACTS OF HEALTH WARNING LABELS ON SOCIODEMOGRAPHICS AND SMOKING-RELATED VARIABLES, BY COUNTRY AND POOLED



* Estimates shown for age and education are beta coefficients, not odds ratios, and thus, the value of an age or education coefficient under the null hypothesis is 0 , not I

${ }^{\mathrm{a}} p<0.01 ;{ }^{\mathrm{b}} p<0.05$; $^{\mathrm{c}} p<0.00$ I 
smoking a cigarette when he was about to light one (Table III). Results were generally consistent with those found for the models estimating factors associated with the cognitive impact of HWLs, including the inverse association with education in Brazil $(B=-0.29, p<0.001)$ although this was also found for Uruguay $(B=-0.20$, $p<0.05)$. In pooled models, Uruguayans were less likely, and Brazilians more likely than Mexicans to report this outcome $\left(\mathrm{AOR}_{\mathrm{UY} \mathrm{vs} \mathrm{MX}}=0.65, \mathrm{p}<0.001 ; \mathrm{AOR}_{\mathrm{BR} \text { vs } \mathrm{MX}}=2.01\right.$, $p<0.001)$. In the model that tested interactions between country and educational attainment, results indicated that the inverse association between education and behavior in Brazil was significantly different from the lack of association found in Mexico.

\section{Discussion}

The results from this study confirmed key study hypotheses. The salience of HWLs, as indicated by noticing and reading or looking closely at the package, was significantly higher in Uruguay than in either Brazil or Mexico. The length of time since introduction of the newest round of HWLs in each country may help explain the greater salience in Uruguay, as attention to HWLs "wears out" over time, ${ }^{7}$ and they were introduced only 2 years prior to data collection in Uruguay, compared to 4 and 5 years prior in Mexico and Brazil, respectively. However, the greater salience of Uruguayan HWLs is also likely due to its being the only country with HWLs on both the front and back of the pack. The history of tobacco packaging confirms this contention, as a key innovation in cigarette marketing involved the display of brand imagery on both sides of the pack in order to communicate this imagery as frequently as possible. ${ }^{23,24}$ Hence, countries should follow WHO-FCTC guidelines for implementing prominent HWLs on all primary surfaces of the pack..$^{25}$

The salience of text-only Mexican and pictorial Brazilian HWLs was comparable, suggesting that the salience of pictorial HWLs can be reduced to that found for text only HWLs when covering only one side. Other studies have also found equivalent salience of pictorial (Canada and Australia) and text only (United Kingdon) HWLs when they are similarly prominent on both the front and back of the pack. ${ }^{79}$ However, the argument in favor of pictoral HWLs is bolserted by our finding that educational attainment was positively associated with salience in Mexico, but unassociated either Brazil or Uruguay. Text-only HWLs, like those in Mexico, may be more likely to be noticed and read by people at higher levels of educational attainment; thus, text-only HWLs may be less effective with more socioeconomically disadvantaged smokers. Indeed, the potential to overcome health literacy issues is one of the key advantages of pictorial warnings over text-only warnings.

Our results also suggest that the Brazilian strategy of using depictions of human suffering and gruesome bodily impacts of smoking on its HWLs had a greater cognitive and behavioral impact than either the abstract imagery used in Uruguay or the text-only HWL format used in Mexico. This is consistent with experimental research, ${ }^{14}$ although it has not been studied before in surveys because countries' pictorial HWL systems have not been distinct enough to allow for such a comparison. ${ }^{9}$ The abstract imagery used in Uruguay appears to have generated even lower cognitive and behavioral impacts than the text-only Mexican HWLs. Another key finding concerns the inverse association between educational attainment and cognitive and behavioral impacts of HWLs in Brazil and Uruguay, but not in Mexico. In pooled analyses, statistically significant interactions involving education and country suggest that this inverse association is significantly different in Brazil when compared to Mexico - in other words, testimonial and gruesome imagery appears to do a better job of communicating risks and promoting thoughts about quitting to smokers with lower educational attainment than those with higher attainment. This is consistent with other studies of mass media campaigns to promote cessation. ${ }^{20}$ Hence, HWL images that depict the gruesome nature of tobaccorelated disease and those that depict the concrete human suffering from smoking-related consequences may help offset smoking-related disparities across SES groups or, in the case of countries that are only beginning to experience the tobacco epidemic, prevent them from even happening.

In general, Brazilian smokers had higher perceived current and future harms due to smoking, perhaps reflecting the country's longer tobacco control program when compared to Mexico and Uruguay. Our results also indicate that the Brazilians were more likely than Uruguayans or Mexicans to be aware of (93\% vs 39\% and $29 \%$, respectively) and to have used (7\% vs $1 \%$ and $2 \%$, respectively) telephone-based cessation assistance, which is advertised in all Brazilian tobacco control media campaigns and HWLs, but only in media campaigns in Mexico and Uruguiay. Across all three countries, however, those who perceived greater future consequences from smoking were also more likely to respond to HWLs, whether examined in terms of HWL salience, cognitive impact, or behavioral impact. These crosssectional data do not allow determination of whether HWLs generate these concerns about future harm or whether this predisposition contributes to selective attention to HWLs. Longitudinal analyses are needed to determine how HWLs contribute to and interact with 
these perceptions to promote downstream quit attempts. Indeed, a clear determination of the public health impact of different HWL strategies will come from examining their impact on consumption, including quitting.

Although the study results are suggestive of the greater impact of front-of-pack HWLs and the use of emotionally evocative imagery, our interpretations should be tempered by a few additional observations. First of all, HWL characteristics varied in size and positioning, as well as in content. Conclusions about the greater cognitive and behavioral impact of Brazilian than Uruguayan HWLs may be partly explained by Brazilian HWLs covering $100 \%$ of the back of the pack, instead of $50 \%$ of each side. However, our conclusions regarding the greater effectiveness of the Brazilianstyle pictorial HWLs are supported by our finding that Uruguayan content had lower cognitive and behavioral impacts than even the Mexican text-only HWLs that covered less surface area (50\% of the back) than Uruguayan labels. Furthermore, this difference was detected in spite of the overall greater salience of Uruguayan labels. Nevertheless, further research should be conducted to determine whether the imagery of human suffering has a greater impact than gruesome diseased organs, or whether there are synergies between the two that would not be obtained if either one or the other strategy was adopted by itself.

The internal validity of the study may have been compromised by a number of issues, including slightly different response options offered for some variables. Our use of educational attainment as an indicator of SES is incomplete and may not adequately represent this concept. Nevertheless, educational attainment is a reasonable indicator of literacy and the impact of pictorials among populations with low literacy has not been examined previously. In the case of Uruguay and Mexico, whose first wave was fielded around the same time, researchers worked to develop consistent and harmonized translations to reduce measurement biases introduced by survey translation; however, Brazil did not undergo this process as it entered the study at a later date, potentially biasing results in un predictable ways. Differing data collection modes (i.e., telephoneadministered in Brazil and face-to-face in Uruguay and Mexico) may have also biased results. Although the coverage of phone lists in Brazil is quite high (São Paulo $77 \%$, Rio de Janeiro 75,2\% and Porto Alegre 86,6\%.), ${ }^{26}$ smokers without landlines are likely to be from lower SES groups and may respond differently to HWLs than the smokers with lower educational attainment in our sample. Finally, the Brazilian sample included monthly smokers, whereas the Uruguayan and Mexican samples excluded those who smoked less than weekly. However, very few Brazilians smoked monthly, but not weekly, and these few ar unlikely to influence results.

Further research should also account for how smokers' responses to HWLs interact with other features of the tobacco control environment. Cross-country differences in tobacco control environments and histories of education about tobacco could help account for our findings; however, we focused our attention on theorybased mediators of HWL impacts on behavior in order to help rule out this possibility. ${ }^{27}$ Finally, despite the population-based nature of our samples, non-response may have biased the generalizability of our results to the broader population within each country.

Overall, this study confirms WHO Article 11 implementation guidelines that countries should have HWLs that prominently occupy both principal display areas of cigarette packages and include pictorial imagery. ${ }^{25}$ Article 11 guidelines suggest that "culturally appropriate pictures" be used, without further specification. Our results suggest that pictures should include emotionally engaging imagery that illustrates negative consequences, using images of diseased organs or of human suffering. HWLs in each of the three countries have changed or are about to change in ways that will further inform the further evolution of Article 11. In 2009, Brazil implemented a set of HWL images found to promote extreme negative emotions and aversion. ${ }^{16}$ Since 2009, Uruguay includes more gruesome imagery, and the pack space dedicated to HWLs has increased to $80 \%$ on the front and back. In September 2010, Mexico will implement pictorial HWLs that primarily emphasize the health and emotional consequences of smoking on important others. Furthermore, the pictorials will appear on the upper $30 \%$ of the front of the pack, with $100 \%$ of the back dedicated to only text. Like Uruguay, Mexico can renew HWL content on an annual basis. The impact of the periodicity of HWL rotation is not well understood. Longitudinal data from the ITC survey will help understand the impacts of these changes so that other countries can learn from these experiences.

\section{Declaration of conflicts of interest}

We declare that we have no conflicts of interest.

\section{Acknowledgements}

Funding for data collection and analyses on this study came from Consejo Nacional de Ciencia y Tecnología (CONACyT Convocatoria Salud-2007-C01-70032), with additional funding for analysis provided by the National Cancer Institute (P01 CA138389) and an un- 
restricted grant from Johnson \& Johnson. Dr Ernesto Sebrié was supported by the Flight Attendant Medical Research Institute (FAMRI).

\section{References}

I.WHO.WHO report on the global tobacco epidemic, 2008: The MPOWER package. Geneva:World Health Organization, 2008. 2.WHO. Framework Convention on Tobacco Control. Geneva, Switzerland:World Health Organization, Tobacco Free Initiative, 2003. 3. Strahan E, White KS, Fong GT, Fabrigar L, Zanna M, Cameron R. Enhancing the effectiveness of message labels on tobacco packaging:A social psychological perspective. Tob Control 2002; I I: I83-190. 4. Hammond D, Fong GT, MacDonald P, Cameron R, Brown K. Impact of graphic Canadian warning labels on adult smoking behavior. Tob Control 2003;12:391-395

5. O'Hegarty M, Pederson LL, Nelson DE, Mowery P, Gable JM, Wortley P. Reactions of young adult smokers to warning labels on cigarette packages. Am J Prev Med 2006;30(6):467-473.

6. Hammond D, Fong GT, McNeil A, Borland R, Cummings KM. The effectiveness of cigarette warning labels in informing smokers about the risks of smoking: Findings from the International Tobacco Control (ITC) Four Country Survey. Tob Control 2006;15(Supp 3):iii 19-25. 7. Hammond D, Fong GT, Borland R, Cummings KM, McNeil AD, Driezen P. Text and graphic warnings on cigarette packages: Findings from the International Tobacco Control Four Country Study.Am J Prev Med 2007;32(3):210-217.

8. Thrasher JF, Hammond D, Fong GT, Arillo-Santillan E. Smokers' reactions to cigarette package warnings with graphic imagery and with only text:A comparison between Mexico and Canada. Salud Publica Mex 2007;49(Sup 2):S233-S240.

9. Borland R, Wilson N, Fong GT, Hammond D, Cummings KM, Yong H, et al. Impact of graphic and text warnings on cigarette packs: Findings from four countries over five years. Tob Control 2009;18:358-364.

10. Shanahan P, Elliott D. Evaluation of the effectiveness of the graphic health warnings on tobacco product packaging, 2008. Canberra: Australian Government, Department of Health and Ageing, 2009.

II. Fong GT, Hammond D, Hitchman SC. The impact of graphic pictures on the effectiveness of tobacco health warnings. Bull World Health Organ 2009;87:640-3

12. Environics Research Group. Testing new health warning messages for cigarette packages:A summary of three phases of focus group research. Ottawa: Health Canada, 2000.
13. Nimbarte A,Aghasadeh F, Harvey C. Comparison of current US and Canadian cigarette pack warnings. Int Q Community Health Educ 2006;24(I):3-27.

14. Thrasher JF,Allen B, Anaya-Ocampo R, Reynales LM, Lazcano-Ponce EC, Hernández-Avila M.Análisis del impacto en fumadores Mexicanos de los avisos gráficos en las cajetillas de cigarros [Analysis of the impact of cigarette package warning labels with graphic images among Mexican smokers]. Salud Publica Mex 2006;48:S65-S75.

15. Nascimento B, Oliveira L,Vieira A, Joffily M, Gleiser S, Pereira M, et al. Avoidance of smoking:The impact of warning labels in Brazil. Tob Control 2008; 17:405-409.

16. INCA. Brazil: Health warnings on tobacco products - 2009. Rio di Janeiro: Ministereo de Saude, Instituto Nacional de Cancer, 2009.

17. Link B. Epidemiological sociology and the social shaping of population health.J Health Soc Behav 2008;49:367-384.

18.Thrasher JF, Rousu MC, Anaya-Ocampo R, Reynales-Shigematsu LM, Arillo-Santillán E, Hernández-Ávila M. Estimating the impact of graphic warning labels on cigarette packs: The auction method.Addict Behav 2007;32(I2):2916-2915.

19. Niederdeppe J, Fiore MC, Baker TB, Smith SS. Smoking-cessation media campaigns and their effectiveness among socioeconomically advantaged and disadvantaged populations. Am J Public Health 2008;98(5):916 - 924 20. Durkin SJ, Biener L,Wakefield M. Effects of different types of antismoking ads on reducing disparities in smoking cessation among socioeconomic subgroups. Am J Public Health 2009;99(I2):2217-2223. 21. Cavalcante TM. Labelling and packaging in Brazil. Geneva, Switzerland: Organizacion Mundial de Salud, 2003.

22. Korn EL, Graubard BI.Analysis of health surveys. New York:WileyInterscience, 1999.

23. Borland R. Tobacco health warnings and smoking-related cognitions and behaviours. Addiction 1997;92(II): I 427-1435.

24. Brandt AM. The cigarette century: The rise, fall, and deadly persistence of the product that defined America. New York: Basic Books, 2007. 25.WHO. Guidelines for implementation of Article II of the WHO Framework Convention on Tobacco Control (Packaging and labelling of tobacco products). Geneva:World Health Organization, 2009.

26. IBGE. Síntese de Indicadores Sociais - Uma análise das condições de vida da população brasileira. Rio de Janeiro: Instituto Brasileiro de Geografia e Estatística, 2008.

27. Fong GT, Cummings KM, Borland R, Hastings G, Hyland A, Giovino $\mathrm{GA}$, et al. The conceptual framework of the International Tobacco Control Policy Evaluation Project. Tob Control 2006; I5(Supp 3):iii3-iiil I . 